\title{
EDUCAÇÃO PROFISSIONAL E PROEJA: PROCESSOS DE ADESÃO E RESISTÊNCIA À IMPLANTAÇÃO DE UMA EXPERIÊNCIA' ${ }^{1}$
}

\author{
Andressa Aita lvo* \\ Álvaro Moreira Hypolito**
}

RESUMO: $\mathrm{O}$ artigo discute os processos de adesão e resistência docentes na implantação de um curso do PROEJA - Programa Nacional de Integração da Educação Profissional com a Educação Básica na Modalidade de EJA - em uma escola agrícola federal. Foi um estudo qualitativo, com análise de documentos e de entrevistas com docentes e coordenadores que acompanharam o processo de criação do curso. Os docentes manifestam diferentes formas de adesão e resistência ao programa, manifestações que se expressam em distintos posicionamentos com relação ao Curso e sua organização pedagógica, à prática pedagógica, ao projeto político-pedagógico e ao dia a dia das aulas. As resistências ao programa deixam lacunas na formação dos alunos, como indicado nos depoimentos dos professores. Todavia, percebe-se que a resistência ao Programa, por parte de alguns, foi diminuindo à medida que se envolveram com o curso, mas trata-se de um processo lento, contínuo e vulnerável a ações externas.

Palavras-chave: PROEJA; Educação Profissional; Educação de Adultos; Adesão; Resistência.

\section{VOCATIONAL AND ADULT EDUCATION: ADHERENCE AND RESISTANCE TO THE IMPLEMENTATION OF A PROGRAM}

ABSTRACT: This article discusses teachers' adherence and/or resistance to the implementation of a vocational education program named 'PROEJA', addressed to young and adult students, in a Federal Agricultural School. Qualitative methodology research was used with documental analysis and interviews with teachers and staff engaged in the program. Teachers manifest several ways of adherence and resistance to the program, expressing their different positions regarding the course and its pedagogic organization and practices, political-pedagogic project, and daily class experience. According to the interviewees, resistance to the program may promote a gap in the students' education. However, resistance has decreased in some cases, as teachers get involved in the course; but it is a slow process, vulnerable to external influences.

Keywords: PROEJA; Vocational Education; Adult Education; Adherence; Resistance.

\footnotetext{
*Doutoranda em Educação na Universidade Federal de Pelotas (UFPel), como Bolsista do Conselho de Aperfeiçoamento CAPES. E-mail: dessaaita@yahoo.com.br

* *Doutor em Currículo pela Universidade de Wisconsin-Madison/EUA; Professor Associado da Universidade Federal de Pelotas (UFPel); Professor Visitante na Universidade Federal de Minas Gerais (UFMG) durante 0 ano letivo 2011-2012; Bolsista de Produtividade do Conselho Nacional de Desenvolvimento Científico e Tecnológico (CNPq). E-mail: alvaro.hypolito@gmail.com
} 
O atual momento do capitalismo, após uma grande fase de expansão, vive um momento de crise. Suas principais estratégias de superação incluem o neoliberalismo, a globalização e a reestruturação produtiva, que redefiniram o papel do Estado e das políticas educacionais (MÉSZAROS, 2008; HARVEY, 1992, 2008). O Estado passa por um processo de reestruturação, construindo um novo cenário para suas políticas. Conforme Oliveira (2009), a grande marca das atuais reformas é a descentralização administrativa, financeira e pedagógica, tendo como resultado um significativo repasse de responsabilidades para o nível local, através da transferência de ações e processos de implementação, atribuindo grande relevância à gestão baseada na eficiência.

Com efeito, o Estado tem desencadeado uma série de ações e a educação tem sido um importante setor de distribuição de políticas públicas, nos seus diversos níveis, seja na Educação Básica, no Ensino Superior ou na Educação Profissional. Nos últimos anos, essas políticas aparecem de forma ambígua, na medida em que há um acirramento dos embates em torno da hegemonia. Algumas políticas continuam com as características neoliberais advindas com a reestruturação, enquanto outras aparecem com traços progressistas dada a pressão de movimentos envolvidos com a educação popular.

A Educação de Jovens e Adultos é uma dessas áreas que tem recebido atenção das políticas públicas, tanto com sua inclusão no FUNDEB quanto como programas especiais, tais como o PROEJA. Nesse sentido, foi estruturado o Programa Nacional de Integração da Educação Profissional com a Educação Básica na Modalidade de Educação de Jovens e Adultos (PROEJA), instituído pelo MEC/SETEC, em 2005.

O Conjunto Agrotécnico Visconde da Graça (CAVG/UFPel) ${ }^{2}$ passou, a partir daí, a implementar o programa PROEJA, com a oferta do Curso Técnico de Vestuário: Modelagem e Confecção. Este estudo teve como objetivo analisar os processos de adesão e de resistência dos docentes em relação à implantação do curso.

A pesquisa adotou uma abordagem qualitativa, com dados documentais (decretos, documento base e matriz curricular) e entrevistas semiestruturadas com o coordenador e docentes da área de formação geral e da área técnica do curso, totalizando oito sujeitos, escolhidos aleatoriamente. A fim de preservar a identidade dos sujeitos, não houve distinção entre 
a coordenação e docentes, tampouco quanto ao gênero, sendo todos denominados pelo título de professor e por um nome fictício.

\section{REFORMAS DO ESTADO E SUAS ARTICULAC̣ÕES COM O CAMPO EDUCACIONAL}

As políticas educacionais e as políticas públicas, ainda que identificadas com a construção de uma sociedade democrática, justa e igualitária, são produzidas em um determinado modelo socioeconômico, o que faz com que políticas públicas de governo sejam em muito definidas pelas políticas de Estado. Desde as últimas décadas do século XX, o Estado vem passando por profundas transformações, sendo reorganizado e (re)contextualizado na tentativa de superar a crise do Estado de Bem-Estar Social, seguindo critérios e objetivos neoliberais. Tais modificações têm repercussão nos diferentes contextos sociais e econômicos, manifestando-se também no campo educacional.

A passagem citada por Apple esclarece de forma inequívoca as políticas educacionais neoliberais:

As iniciativas neoliberais são caracterizadas como políticas de livre mercado que encorajam a empresa privada e a opção do consumidor, recompensam a responsabilidade individual e a iniciativa pessoal e procuram destruir a mão morta do governo incompetente, burocrático e parasitário que nunca faria o bem intencionado, o que raramente é. (APPLE, 1999, p. 21).

Essas políticas cada vez mais se sedimentam nos diversos contextos, a partir de um discurso hegemônico, com o objetivo de reconstituir o senso comum com vistas a demonstrar que este é o sistema mais articulado às novas necessidades dos mercados globalizados e de intensa competitividade.

É fácil observar a forte influência das agências internacionais nesse panorama social, político e econômico, em especial a do Banco Mundial. Como pontua Soares (1998), o Banco Mundial exerce forte influência nos rumos do desenvolvimento mundial, sua importância deve-se, além de seus empréstimos e abrangência de suas áreas de atuação, ao caráter estratégico que desempenha no processo de reestruturação neoliberal dos países em desenvolvimento, por meio de políticas de ajuste estrutural. 
Torres (1998) ressalva o fato de o Banco Mundial ter-se tornado, nos últimos anos, o organismo com maior visibilidade no panorama educativo global, transformando-se na principal agência de assistência técnica em matéria de educação para os países em desenvolvimento. Com o intuito de melhorar o acesso, a equidade e a qualidade dos sistemas escolares, o Banco apresenta pacotes de medidas, em especial para o ensino de primeiro grau, como se pode ver em Hypolito (2008), a fim de estimular os países a concentrarem recursos públicos na educação básica.

Coraggio (1998) tece algumas considerações acerca da influência do Banco Mundial no contexto educacional, mostrando que, para o Banco adequar a realidade educativa a seu modelo econômico e poder aplicar seus teoremas gerais, promove certas correlações, tais como: sistema educativo e sistema de mercado, escola e empresa, pais e consumidores de serviços, aprendizagem e produto, desconsiderando aspectos fundamentais da realidade educativa.

Em suma, de acordo com Shiroma, Moraes e Evangelista (2000):

o Banco Mundial recomenda mais atenção aos resultados, sistema de avaliação da aprendizagem, inversão em capital humano atentando para a relação custo-benefício; propõe, além da descentralização da administração das políticas sociais, maior eficiência no gasto social, maior articulação com o setor privado na oferta de educação. (p. 74)

$\mathrm{Na}$ visão neoliberal, os sistemas educacionais enfrentam uma profunda crise de eficiência, eficácia e produtividade, caracterizada por uma crise de qualidade em virtude da improdutividade que caracteriza as práticas pedagógicas e a gestão administrativa da maioria das escolas. Sob essa perspectiva, não existe uma crise de democratização, mas uma crise gerencial (GENTILI, 1996).

Esta crise para ser superada necessita da realização de uma grandiosa reforma administrativa do sistema escolar, com vistas a melhorar a qualidade dos serviços educacionais. Assim, um determinado discurso hegemônico tem embasado a grande maioria das reformas educacionais: devemos melhorar o padrão de qualidade, aumentar o grau de cobrança em relação aos professores, criar índices desejáveis de educação, além de introduzir mais provas nas escolas. 
O neoliberalismo formula um conceito específico de qualidade, decorrente das práticas empresariais e transferido, sem mediações, para o campo educacional. Impõe, assim, a perspectiva de que soluções de mercado irão suprir as necessidades educacionais. $\mathrm{O}$ neoliberalismo conceitua qualidade a partir de uma perspectiva em que educação é vista a partir de uma ótica pragmática, gerencial-administrativa e economicista.

Por este paradigma, o Estado desvia a culpa das desigualdades, muito evidentes no acesso e no resultado, para as escolas, pais e crianças individuais, transferindo as responsabilidades para as escolas (APPLE, 2003). Como consequência, as escolas passam a depender do resultado de seus alunos para melhorar seus indicadores; as escolas que desejam manter ou melhorar sua posição de mercado procuram selecionar os melhores alunos, assegurando que determinados tipos de alunos com determinadas características sejam aceitos e determinados tipos de alunos sejam descartados, reforçando as desigualdades sociais nos sistemas de ensino. Essas reformas tendem a ignorar o fato de que as características externas às escolas, como pobreza, poder político e econômico, explicam muitas vezes melhor a variação no desempenho escolar do que a suposta garantia de uma escola eficiente (APPLE, 2003).

Ball (2005) afirma que o gerencialismo desempenha o papel de destruir os sistemas ético-profissionais que prevaleciam nas escolas, provocando sua substituição por sistemas empresariais competitivos, além de buscar incutir uma lógica de performatividade na alma do trabalhador.

Assim, esse novo paradigma de políticas públicas educacionais segue também a lógica da performatividade, a qual, segundo Ball (2004), facilita o monitoramento do Estado, que governa a distância e se insere nas culturas e práticas das instituições dos setores públicos, como nas subjetividades dos trabalhadores, de modo que nem percebam. A performatividade reforça os conceitos de resultado, desempenho, qualidade, de tal forma que os desempenhos de sujeitos individuais ou de organizações servem como parâmetros de produtividade ou de resultado.

É perceptível a influência das diretrizes econômicas nos sistemas educacionais, tanto em sentido macro, por meio de políticas públicas, como em sentido micro, nas gestões escolares. Nesse contexto, retomando o que já foi dito anteriormente, as reformas educacionais ainda estão sendo regidas sob orientação de organismos financeiros internacionais e com forte inspiração neoliberal. No campo da educação profissional e de adultos, o 
foco tem sido a preparação para o trabalho, nas diferentes versões, ora como formação profissionalizante obrigatória, ora como preparação para o trabalho, ora como educação para a empregabilidade. Esta última mais sincronizada com os ditames neoliberais.

A educação técnica e profissional, especialmente nos centros federais de educação, agora IFs, tem sido amplamente discutida com foco na educação integrada - ensino técnico/ensino médio - ou educação subsequente ou concomitante. Ora a discussão versou sobre modelos de ensino, por módulos ou por currículo seriado, ora sobre o tipo de oferta, etc.

É neste contexto de inúmeras reformas da educação profissional, muitas orientadas para a empregabilidade e para o mercado, que surge o PROEJA, como inovação. As propostas de políticas já estruturadas para Educação de Jovens e Adultos e Qualificação Profissional remetem-nos ao seguinte panorama: por um lado, a orientação das agências internacionais no sentido de propor uma educação separada entre Formação Profissional e Ensino Regular, voltada para o mercado, destinada a formar mão de obra; e, por outro lado, a tradição do pensamento crítico em educação, no Brasil, que sempre se posicionou com uma crítica radical a tais modelos, em direção a uma integração da Educação Profissional com o Ensino Regular. Nesse sentido, há uma clara tensão entre as lutas históricas e as políticas públicas, num embate em torno da definição do conteúdo das políticas educativas nesse campo.

\section{PROGRAMA NACIONAL DE INTEGRAÇÃO DA EDUCAC̣ÃO PROFISSIONAL COM A EDUCAÇÃO BÁSICA NA MODALIDADE DE EDUCAĈ̣̃O DE JOVENS E ADULTOS - PROEJA}

A educação no Brasil tem sido marcada pela desigualdade social, cultural e econômica. Essa desigualdade histórica fez com que a escolarização ocorresse de forma desigual. Por esta razão, a Educação de Jovens e Adultos (EJA) representa uma dívida social para com os que não tiveram acesso à educação e a bens sociais, na escola ou fora dela (DI PIERRO, 2001). Somente a partir da Constituição Federal de 1988 que o direito à Educação Básica foi estendido aos jovens e adultos. 
A Educação de Jovens e Adultos vem sendo vista com duas grandes funções:

\begin{abstract}
a função reparadora que deve ser vista, ao mesmo tempo, como uma oportunidade concreta de presença de jovens e adultos na escola e uma alternativa viável em função das especificidades socioculturais destes segmentos para os quais se espera uma efetiva atuação das políticas sociais e uma função equalizadora que dará cobertura a trabalhadores e a tantos outros segmentos sociais como donas de casa, migrantes, aposentados e encarcerados. A reentrada no sistema educacional dos que tiveram uma interrupção forçada seja pela repetência ou pela evasão, seja pelas desiguais oportunidades de permanência ou outras condições adversas, deve ser saudada como uma reparação corretiva, ainda que tardia, de estruturas arcaicas, possibilitando aos indivíduos novas inserções no mundo do trabalho, na vida social, nos espaços da estética e na abertura dos canais de participação. (BRASIL, 2000, p. 9).
\end{abstract}

A Conferência Mundial, em Jontien, que aprovou a Declaração Mundial sobre Educação para Todos, também concedeu um destaque à educação de jovens e adultos, incluindo metas relativas à redução de taxas de analfabetismo, além da expansão dos serviços de educação básica e capacitação aos jovens e adultos, com avaliação sobre seus impactos sociais.

Apesar de ainda restar várias questões pertinentes a um debate acerca da efetividade e natureza da educação de jovens e adultos e sua relação com o ensino fundamental e médio, passaremos a analisar questões referentes à educação de jovens e adultos e à educação profissional, de modo mais específico.

O Governo Federal, por meio do Decreto no 5.478/2005 (BRASIL, 2005), instituiu o Programa Nacional de Integração da Educação Profissional com a Educação Básica na Modalidade de Educação de Jovens e Adultos - PROEJA, para a rede federal de ensino técnico profissional, especificando o número de vagas e carga horária destinada aos cursos desta modalidade.

Logo após a criação e instituição do PROEJA, professores e pesquisadores envolvidos com a temática do Decreto passam a discutir esta nova modalidade de ensino e questionar vários aspectos da forma de sua implantação. Com o intuito de responder às inquietudes demonstradas quanto ao caráter compulsório e outros aspectos, o Governo Federal promulgou o Decreto $n^{\circ}$ 5.840, de 13 de julho de 2006 (BRASIL, 2006 a), em substituição ao Decreto anterior, trazendo várias modificações ao programa, que passa 
a atender, não apenas, ao Ensino Médio, mas estende-se a toda Educação Básica. As instituições deveriam ainda disponibilizar ao PROEJA, desde 2006, no mínimo dez por cento do total das vagas de ingresso da instituição, tomando como referência o quantitativo de matrículas do ano anterior, ampliando essa oferta a partir do ano de 2007.

Em 2006 foi elaborado o Documento Base, com vistas a refletir sobre a problemática da Educação Básica Brasileira, em especial questões referentes à EJA, além de nortear a construção do projeto político-pedagógico dos cursos.

O Documento Base apresenta a situação da Educação de Jovens e Adultos no Brasil; as políticas públicas até então destinadas a este grupo; os desafios da implantação de uma política de integração da educação profissional técnica de nível médio e o ensino médio na modalidade EJA; concepções e princípios acerca do programa; o projeto político-pedagógico integrado e questões referentes a aspectos operacionais do programa.

Dentre as discussões e reflexões propostas pelo Documento Base, identifica-se a proposta de formação integral do educando, a partir de um discurso que pretende se afastar da lógica neoliberal:

os processos educativos estruturados a partir desse referencial deverão contribuir para a formação de cidadãos capazes de participar politicamente na sociedade, atuando como sujeitos nas esferas públicas, privada e no terceiro setor, espaços privilegiados da prática cidadã, em função de transformações que apontem na direção dessa sociedade justa e igualitária (BRASIL, 2006b, p. 24).

O programa visa uma formação integral para possibilitar ao aluno a compreensão da realidade social, política, econômica, cultural e do mundo do trabalho, distanciando-se de uma formação voltada a atender apenas as necessidades do mercado, por intermédio de uma qualificação para o mercado. Ainda de acordo com o Documento Base, "[...] abandona-se a perspectiva estreita de formação para o mercado de trabalho, para assumir a formação integral dos sujeitos, como forma de compreender e se compreender no mundo.”(BRASIL, 2006b).

Nessa perspectiva, a relação entre educação profissional, ensino médio e EJA, segundo o Documento Base, sinaliza a busca de uma forma integrada, que se traduz por um currículo integrado: 
é uma possibilidade de inovar pedagogicamente na concepção de ensino médio, em resposta aos diferentes sujeitos sociais para os quais se destina, por meio de uma concepção que considera o mundo do trabalho e que leva em conta os mais diversos saberes produzidos em diferentes espaços sociais (BRASIL, 2006b, p. 43).

Quanto à organização curricular, o Documento Base destaca que esta organização não está dada a priori, que deve ser uma construção contínua, processual e coletiva a fim de envolver todos os sujeitos que participam do programa. Sendo assim:

a EJA abre possibilidades de superação de modelos curriculares tradicionais, disciplinares e rígidos, possibilitando a desconstrução e construção de modelos curriculares e metodológicos, observando as necessidades de contextualização frente à realidade do educando, promovem a ressignificação de seu cotidiano. Essa concepção permite a valorização dos saberes oriundos de outros processos, construídos e adquiridos fora dos espaços educacionais formais (BRASIL, 2006b, p. 48).

Por fim, o PROEJA é uma política inédita no Brasil, que traz diversas inovações nas reflexões e discussões até então realizadas acerca da EJA, além de estabelecer princípios e concepções para esta modalidade de ensino, que confrontam o tipo de formação técnica e profissional que até então vinha sendo desenvolvida.

\section{ADESÃO E/OU RESISTÊNCIA DOCENTE NO CURSO TÉCNICO DE VESTUÁRIO NA MODALIDADE PROEJA}

O PROEJA é um programa em fase de implantação em muitas instituições de ensino, no CAVG esta experiência teve início em 2007 a partir do curso de Vestuário I ${ }^{3}$. Por tratar-se de uma nova modalidade de ensino, desconhecida da maioria dos professores, foram necessários vários debates e discussões acerca da implantação do PROEJA. A implantação ocorreu em meio a diferentes formas de adesão e resistência ao programa, as quais se expressam em distintos posicionamentos com relação ao Curso e sua organização pedagógica, na prática pedagógica dos professores, no projeto político-pedagógico, no projeto curricular, no dia a dia das aulas, no comportamento dos funcionários e demais agentes que compõem o contexto educacional da Instituição. 
A partir de Enguita, podemos entender adesão como a identificação com a instituição escolar com a cultura que ela vincula e, por resistência, podemos entender a negativa coletiva em aceitar as exigências e promessas da escola e sua contraposição com valores alternativos. De acordo com o autor, a adesão e a resistência são práticas coletivas, que contribuem respectivamente para reforçar ou para questionar determinado projeto (ENGUITA, 1989, p. 7).

Observa-se a dedicação e o comprometimento de alguns professores com o PROEJA, em contrapartida percebe-se também a resistência de outros em assumir essa modalidade de ensino, seja em função de se tratar de um programa do Governo Federal, seja em função do público do PROEJA, pois a falta de conhecimento sobre os sujeitos da EJA faz com que os alunos sejam vistos como analfabetos, excluídos, fracassados, etc. Esse desconhecimento propicia um preconceito daqueles que vão trabalhar com o PROEJA, nos diferentes contextos da instituição. Contrapondo-se às diferentes formas de resistência ao novo, é interessante a perspectiva de Freire (1997) de que ensinar exige risco, aceitação do novo e rejeição a qualquer forma de discriminação. É própria do pensar crítico a disponibilidade ao risco, a aceitação do novo que não pode ser negado ou acolhido só porque é novo, assim como o critério de recusa ao velho não é apenas o cronológico (FREIRE, 1997, p. 39).

A partir dos relatos dos professores, pode-se estabelecer algumas considerações acerca da adesão e da resistência ao PROEJA durante a sua implantação como demonstra o seguinte depoimento:

[...] é uma modalidade diferente, o Curso de Vestuário regular tem uma abrangência bem maior, este PROEJA é mais direcionado para uma modalidade, então eles [alunos] saem técnicos como os outros, mas com uma área mais limitada. (Professor Daniel).

A declaração do professor Daniel representa uma das formas de resistência docente em aceitar e aderir a essa nova modalidade de ensino, pois, segundo ele, o PROEJA não possui a mesma legitimidade dos outros cursos, sendo recebido como um curso que apresenta uma inferioridade em relação ao Curso de Vestuário I. As considerações do professor Daniel quanto à certificação dos alunos demonstram a sua percepção de que, embora os cursos tenham a mesma denominação e ambos os alunos sejam técnicos, as competências dos alunos do PROEJA não são iguais às competências dos alunos do Curso de Vestuário I. 
As considerações de outros professores remetem a uma resistência inicial ao PROEJA, na fase de implantação do curso, crescendo a adesão no decorrer das aulas:

Eu notei no início que houve uma certa reserva, o pessoal não tava muito ... parece que preparado para trabalhar com o PROEJA e parecia que seria uma coisa muito difícil da gente trabalhar, que não ia dar retorno, assim ninguém estava apostando nesta turma, mas a gente que trabalhou achou assim, que é diferente, eu gostei muito (professor Marcos).

[...] o professor apresenta uma resistência no começo, mas depois o professor adapta os seus métodos pra tentar fazer com que eles tenham um bom rendimento. (Professor Artur).

Os depoimentos acima mostram que existe uma resistência inicial ao PROEJA, proveniente da falta de experiência com esta modalidade de ensino. Para alguns professores, tratava-se de uma experiência inovadora na Instituição, o que pode lhes ter causado certo receio.

Para Tardif (2002), os saberes experienciais ou práticos tornam-se os saberes próprios do professor e da sua vida educacional, este saber incorpora a experiência individual e coletiva. Nesta perspectiva,

o professor ideal é alguém que deve conhecer sua matéria, sua disciplina e seu programa, além de possuir certos conhecimentos relativos às Ciências da Educação e à Pedagogia e desenvolver um saber prático baseado em sua experiência cotidiana com os alunos (TARDIF, 2002, p. 39).

A incorporação de novas experiências com o curso permitiu que alguns professores modificassem seu comportamento em relação ao curso e aos alunos, passando de uma posição de nítida resistência a um comportamento mais próximo a uma aceitação do projeto.

Outros relatos demonstram uma resistência inicial ao PROEJA, ou à implantação de uma política externa à instituição, elaborada desde fora e imposta:

No início, como era uma coisa nova, todos os cursos ficaram meio assim, foi uma coisa meio que uma sugestão que fosse o Curso de Vestuário, porque está mais estruturado, organizado, começa e aí a gente se acha um pouco incapar, mais uma turma e uma turma diferenciada, mas foi um desafio e depois que a gente aceitou, a gente trabalhou em cima disso, e foi bem, todos os professores trabalharam, todos, não ficou nenbum de fora, então o nosso grupo todo trabalbou. (Professor Gabriel). 
[...] é difícil, porque... assim, é fácil para o governo oferecer novos cursos e novas inserções, vamos dizer assim, para os alunos [...] (Professor Daniel).

Os depoimentos dos professores Gabriel e Daniel referem-se ao fato das políticas serem elaboradas em um contexto externo à instituição e depois inseridas no contexto da escola, de tal modo que os professores precisaram se adaptar à política e não o contrário. Nessa perspectiva é que Ball (2006) afirma que nós tendemos a tomar por certo o ajuste de professores e do contexto à política e não da política ao contexto. $\mathrm{O}$ autor considera que algumas políticas alteram algumas das circunstâncias nas quais trabalhamos, mas não podem mudar todas as circunstâncias.

Para outros professores, existe uma resistência permanente por parte de alguns colegas em trabalhar com o PROEJA, como afirma o professor Beto:

[...] existe resistência, tem professores que não gostam, não querem, não centra, mas a gente percebe, tem colegas que odeiam. [...] eu acho dificil para o professor, é difícil, eu acho muito difícil dar aula para o PROEJA. (Professor Daniel).

As declarações dos professores Beto e Daniel nos remetem a uma resistência dos professores em se adequar às necessidades desses alunos. Trabalhar com o PROEJA exige que revejam suas práticas pedagógicas, pois se trata de um público que possui peculiaridades. O que se observa, em certos casos, é uma resistência ao Programa em razão das mudanças e transformações na prática pedagógica que este pode lhes exigir. Contudo, é sabida a necessidade do professor estar continuamente pensando e repensando sobre sua prática, Freire (1997) reforça essa ideia ao afirmar que é pensando criticamente a prática de hoje ou de ontem que se pode melhorar a próxima prática. As mudanças e transformações são necessárias a uma prática pedagógica adequada aos diferentes contextos culturais e sociais.

A resistência dos professores em trabalhar com o PROEJA pode ser também em função do comportamento dos alunos do Curso, conforme enuncia o professor Hélio no trecho que segue:

Quanto aos professores, têm uma resistência, talvezporque eles exigem muito do professor, eles estão sempre na porta da sala dos professores perguntando, eles não são como aqueles alunos que vêm porque têm que vir, eles vêm porque querem aprender, então eles querem te sugar ao máximo, então de repente por se tratar deste tipo de aluno eu acho que os professores... Ah! Tem que dar aula no PROEJA, eu acho que tem isso sim. 
O aluno do PROEJA, por diversas razões, apresenta um comportamento que se diferencia dos demais alunos, rompendo com a cultura escolar estabelecida. Em geral, são alunos mais maduros, que retornam às instituições de ensino por vontade própria, e, portanto, buscam continuamente por novos conhecimentos. Freire (1997) salienta a importância de se atender as curiosidades dos alunos, pois a curiosidade deve ser vista como uma inquietação indagadora, como a procura de esclarecimento, e o professor não deve se intimidar frente aos questionamentos, temendo o seu desconhecimento do que lhe é questionado, o fundamental é o professor saber conviver com os diferentes e não temer essa relação. Todavia, na prática escolar cotidiana nem sempre há condições para isso.

Um dos entrevistados, ao expor sua opinião acerca da resistência ao Programa, refere-se a outra forma de resistência, velada, que para ele aparece mesmo quando não quer ser revelada, como relata seu depoimento:

[...] é assim ó, isso em alguns momentos não fica muito claro, não é, mas assim, às vez̧es a gente tem opção de escolha de turmas, e não é todo mundo que tem assim essa vontade de trabalhar com o PROEJA. (Professor Francisco).

Nem sempre a resistência ao PROEJA é declarada pelo professor, contudo pode ser identificada a partir de suas ações, como, por exemplo, ao se abster na escolha de trabalhar com as turmas de PROEJA.

Apesar da constatação de que existe resistência por parte de alguns professores em relação ao PROEJA, observa-se também que alguns professores aderiram ao programa:

[...] eu sou suspeita para falar porque eu gosto, eu não tenho essa resistência, eu acho gratificante. (professor Beto).

Olha eu gostei muito, a turma é muito boa, assim, eles querem muito aprender, procuram muito, então eu gostei muito de trabalhar com eles. (Professor Marcos).

A análise dos relatos pesquisados deixa claro que há processos de resistência e de adesão. A resistência ao PROEJA existe e manifesta-se de diferentes maneiras e por diversas razões, tais como: o desconhecimento acerca da modalidade de ensino, a dificuldade dos professores em inserir novas práticas pedagógicas, os pré-conceitos em relação ao público da EJA, a inserção de uma política externa à instituição, entre outros, como apontaram os depoimentos.

Entretanto, a resistência ao PROEJA e seus desdobramentos não é uma condição permanente e inalterada, com o decorrer do curso, a partir da relação professor-aluno, constata-se que a adesão ao programa 
foi aumentando. Alguns professores, por opção própria, trabalharam com os alunos durante os três anos do curso, devido à boa experiência que os semestres anteriores com a turma lhe oportunizaram, assim, para a maioria dos professores, a experiência de trabalhar com o PROEJA foi aparentemente gratificante.

A adesão ao PROEJA é um processo contínuo e permanente, pois foi necessária uma quebra de paradigmas por parte dos professores que apresentaram maior resistência ao Programa. Tais professores, precisaram se adaptar a esta nova modalidade de ensino e as suas especificidades. Como salienta o depoimento do professor Gabriel:

Eu tinha muito receio se eu ia conseguir fazer eles entenderem, eu aprendi como professor, claro eles também aprenderam, mas eu tenho um carinho muito grande por eles [...]

Estas considerações demonstram que inicialmente o professor Gabriel possuía uma resistência, foi necessária uma mudança de comportamento, novas práticas pedagógicas, um reconhecimento da turma, e, com o decorrer das aulas, o professor foi aderindo ao programa. O processo de ensino aprendizagem passou por um reconhecimento dos sujeitos envolvidos, para, aos poucos, haver um intercâmbio de conhecimentos e informações entre o professor e a turma.

Esse fenômeno é explicado por Marques ao afirmar que:

$\mathrm{Na}$ mediação da docência em sala de aula é que se efetivam as aprendizagens formais e sistemáticas e os conteúdos delas adquirem vida ao serem assumidos na qualidade de elementos determinados do conhecimento alcançado no entendimento compartilhado por professores e alunos, sujeitos/atores do seu ensinar e aprender. Os alunos com seus saberes da vida e o professor, além dos saberes da própria experiência vivida, com o saber organizado e sistematizado, sob a forma escolar e em função dela, na cultura e nas ciências. (MARQUES, 2006, p. 111).

A adesão ao PROEJA não ocorreu de forma imediata, na realidade trata-se de um processo lento, que envolve os diversos sujeitos inseridos neste contexto e nem sempre é desejável ou atingida por alguns docentes. Para que ocorra uma adesão, é necessário que se transponha paradigmas que há muito tempo estão presentes no contexto educacional. Essa predisposição não envolve somente uma mudança prática que mais cedo ou mais tarde vai ocorrer, envolve também uma visão política e de mundo que, muitas vezes, está cristalizada como conservadora. 
Portanto, a adesão ao programa não se encerra em um momento determinado, trata-se de um processo permanente que, a todo o momento, está sujeito a interferências. Poderá ser a partir das experiências com as turmas de PROEJA que as instituições de ensino e todos os agentes envolvidos poderão aos poucos diminuir a resistência a esse programa.

O processo é tão paradoxal que, apesar do aumento da adesão dos professores em relação ao PROEJA, o Curso de Vestuário não terá uma nova turma, o que põe em dúvida se o que há é uma resistência velada ou uma adesão velada, ou ambos. Tal decisão foi tomada pela coordenação juntamente com os professores, alegando problemas de infraestrutura, como argumentam os seguintes relatos:

[...] o que nos restringe na questão de aumentar o número de turmas, é o numero de professores, número de professores e espaço aqui, de sala de aula mesmo. $O$ recurso que veio do governo federal foi só pra matéria-prima, só material de consumo, material pra eles, eles usam tesoura, agulhas, essas coisas, então material pra eles que foi disponibilizado e material de consumo. Então assim, não é dizer que a gente não queira, é que eu acho que a gente não tem espaço físico, não comporta. (Professor Carlos).

O problema da falta de infraestrutura parece ser significativo, seja em parte pela falta de apoio e mais investimento federal no Programa PROEJA, seja pela falta de compromisso da administração central da escola. Isso passa a ser um empecilho para novas turmas de PROEJA. Existe também um acordo entre os cursos técnicos da instituição, que prevê um rodízio: a cada ano uma nova turma de PROEJA oferecida pelos cursos técnicos existentes, na forma de rodízio. Como ilustram as considerações do professor Carlos:

Até então a escola tem 3 cursos, o de vestuário, agroindústria e agropecuária, vestuário e agroindústria já ofereceram, então agora o curso de agropecuária, por eliminação, é o ultimo que falta. [...] é, na verdade a gente tá seguindo um cronograma, né, então a proposta foi essa, nós iniciaríamos, depois seria... na verdade quando nós iniciamos nem tinha a previsão de que o próximo seria a agroindústria, seria outro curso, que seria disponibilizado, né? Então, a principio, por enquanto a gente tá seguindo um cronograma que foi acertado no inicio. (Professor Carlos)

Apesar das justificativas trazidas pelo professor Carlos para a não abertura de novas turmas no curso de Vestuário, ainda assim, esse discurso demonstra que existe uma resistência ao programa. Ademais, o rodízio mostra que não há uma preocupação com a continuidade e com a criação de competências nessa área para consolidar um projeto de escola. 


\section{CONSIDERACְ̃̃ES FINAIS}

A educação profissional é um dos centros da atenção das políticas educacionais orientadas para a empregabilidade e para atender ao mercado, conforme a lógica neoliberal. O programa PROEJA parece caminhar no sentido oposto ao preconizado por essa lógica e tenta recuperar a longa trajetória de educadores no sentido de articular, de forma crítica, educação profissional e formação geral.

Este embate político reflete-se nas ambiguidades das políticas e na forma como o programa chegou às escolas e como foi recebido pelos atores escolares.

Ao se analisar as atitudes docentes em relação à implantação do curso Técnico em Vestuário na modalidade PROEJA, o que se percebe é a existência de diferentes formas de adesão e resistência ao programa, manifestações que se expressam em distintos posicionamentos com relação ao Curso e sua organização pedagógica, à prática pedagógica, ao projeto político-pedagógico e ao dia a dia das aulas.

As resistências ao programa deixam lacunas na formação dos alunos, que se expressam de várias formas nos depoimentos dos professores. Todavia, percebe-se que a resistência ao Programa, por parte de alguns, foi diminuindo à medida que se envolveram com o curso, contudo trata-se de um processo lento, contínuo e vulnerável a ações externas.

A manutenção do PROEJA como programa depende de uma ação mais contundente por parte do governo, no sentido de garantir financiamento adequado e transformá-lo em política educacional. Contudo, para obter sucesso, tudo indica a necessidade de uma ação mais cotejada com as escolas e com os atores que efetivamente implementam essas políticas na escola. 


\section{REFERÊNCIAS}

APPLE, M. Política Cultural e Educação. São Paulo: Cortez, 1999.

APPLE, M. Educando à direita: mercado, padrões, Deus e desigualdade. São Paulo: Cortez; Instituto Paulo Freire, 2003.

BALL, S. J. Performatividade, privatização e o pós-Estado do bem-estar. Educação Sociedade, Campinas, v. 25, n. 89, p. 1105-1126, set./dez. 2004. http://dx.doi.org/10.1590/ S0101-73302004000400002

BALL, S. J. Profissionalismo, gerencialismo e performatividade. Cadernos de Pesquisa, São Paulo, v. 35, n. 126, p. 539-564, set./dez. 2005. http://dx.doi.org/10.1590/S0100-15742005000300002 BALL, S. J. Sociologia das políticas educacionais e pesquisa crítico-social: uma revisão pessoal das políticas educacionais e da pesquisa em política educacional. Currículo sem Fronteiras, Pelotas, v. 6, n. 2, p. 10-32, jul./dez. 2006.

BRASIL. Conselho Nacional de Educação. Câmara de Educação Básica. Parecer no 11, de 10 de maio de 2000. Dispõe sobre as Diretrizes Curriculares Nacionais para a Educação de Jovens e Adultos. Diário Oficial da República Federativa do Brasil, Brasília, DF, 9 jun. 2000. Seção 1.

BRASIL. Congresso Nacional. Decreto no 5.478, de 24 de junho de 2005. Institui, no âmbito das instituições federais de educação tecnológica, o Programa de Integração da Educação Profissional ao Ensino Médio na Modalidade de Educação de Jovens e Adultos - PROEJA. Diário Oficial da República Federativa do Brasil, Brasília, DF, 27 jun. 2005. Seção 1.

BRASIL. Congresso Nacional. Decreto no 5.840, de 13 de julho de 2006. Institui, no âmbito federal, o Programa Nacional de Integração da Educação Profissional com a Educação Básica na Modalidade de Educação de Jovens e Adultos - PROEJA, e dá outras providências. Diário Oficial da República Federativa do Brasil, Brasília, DF, 14 jul. 2006a. Seção 1. BRASIL. Ministério da Educação. Secretaria de Educação Profissional e Tecnológica. Programa de Integração da Educação Profissional Técnica de Nivel Médio na Modalidade de Educação de Jovens e Adultos - PROEJA. Brasília: MEC, 2006b. Documento Base.

CORAGGIO, J. L. Propostas do Banco Mundial para a educação: sentido oculto ou problema de concepção? In: TOMMASI, L.; WARDE, M. J.; HADDAD, S. (Orgs.). O Banco Mundial e as politicas educacionais. 2. ed. São Paulo: Cortez, 1998. p. 75-123.

DI PIERRO, M. C. et al. Visões da Educação de Jovens e Adultos no Brasil. Cadernos Cedes, Campinas, v. 21, n. 55, p. 58-77, nov. 2001. http://dx.doi.org/10.1590/ S0101-32622001000300005

ENGUITA, M. F. Educação e teorias da resistência. Educação e realidade, Porto Alegre, v. 14, n. 1, p. 3-16, jan./jun. 1989.

FREIRE, P. Pedagogia da autonomia: saberes necessários à prática educativa. São Paulo: Paz e Terra, 1997.

GENTILI, P. Neoliberalismo e educação: manual do usuário. In: GENTILI, P.; SILVA, T. T. (Orgs.). Escola S. A. quem ganha e quem perde no mercado educacional no neoliberalismo. Brasília: CNTE, 1996. p. 9-49, p. 167-188.

HARVEY, D. Condição Pós-moderna. 14. ed. São Paulo: Loyola, 1992.

HARVEY, D. Neoliberalismo - bistória e implicações. São Paulo: Loyola, 2008. 
HYPOLITO, A. M. Estado gerencial, reestruturação educativa e gestão educacional. Revista Brasileira de Política e Administração da Educação, Porto Alegre, v. 24, n. 1, p. 63-78, jan./abr. 2008.

MARQUES, M. O. A aprendiragem na mediação social do aprendido e da docência. 3. ed. Ijuí: Ed. Unijuí, 2006.

MÉSZAROS, I. A Educação para além do Capital. 2. ed. São Paulo: Boitempo Editorial, 2008. OLIVEIRA, D. A. As políticas educacionais no governo Lula: ruptura e permanência. Revista Brasileira de Política e Administração da Educação, Porto Alegre, v. 25, n. 2, p. 197-209, mai./ago. 2009.

SHIROMA, E. O.; MORAES, M.; EVANGELISTA, O. Politica educacional. Rio de Janeiro: DP\&A, 2000.

SOARES, M. C. C. Banco Mundial: políticas e reformas. In: TOMMASI, L.; WARDE, M. J.; HADDAD, S. (Orgs). O Banco Mundial e as Políticas Educacionais. 2. ed. São Paulo: Cortez, 1998. p. 75-123.

TARDIF, M. Saberes docentes e formação profissional. 3. ed. Petrópolis: Vozes, 2002.

TORRES, R. M. Melhorar a qualidade da educação básica? As estratégias do Banco Mundial. In: TOMMASI, L.; WARDE, M. J.; HADDAD, S. (Orgs.). O Banco Mundial e as Políticas Educacionais. 2. ed. São Paulo: Cortez, 1998. p. 125-193.

\section{NOTAS}

${ }^{1}$ Este texto é resultado de investigação que obteve financiamento CAPES/PROEJA, com auxílio e bolsa de mestrado.

2 Situado no município de Pelotas (RS), o Conjunto Agrotécnico Visconde da Graça (CAVG) foi criado com o nome de Patronato Agrícola Visconde da Graça, no governo Epitácio Pessoa, pelo decreto 15.102 de 9 de novembro de 1921. Posteriormente, passou a ser uma unidade de educação profissional vinculada à UFPel, oferecendo diversos cursos, tais como: cursos profissionalizantes de nível médio integrado e técnico (regular e PROEJA), mais recentemente, cursos de ensino superior e cursos de pós-médio na modalidade a distância. Atualmente, é um dos campi do IFSul.

${ }^{3}$ Com o intuito de facilitar a leitura e compreensão do texto, neste capítulo, o Curso Técnico em Vestuário Integrado ao Ensino Médio e o Curso Técnico em Vestuário Integrado ao Ensino Médio na modalidade PROEJA terão seus nomes respectivamente substituídos por Curso de Vestuário I e Curso de Vestuário II.

Recebido: 07/10/2011

Aprovado: 04/06/2012

Contato:

Universidade Federal de Pelotas Faculdade de Educação Rua Alberto Rosa, 154 CEP $96010-770$ Pelotas, RS Brasil 